J. Lake Sci. (湖泊科学), 2012, 24(3):341-346

http: //www.jlakes.org. E-mail : jlakes@niglas.ac.cn

(C) 2012 by Journal of Lake Sciences

\title{
云南省高原深水湖泊程海磷形态分布和变化
}

\author{
董云仙 ${ }^{1}$, 洪雪花 ${ }^{2}$, 贺 涁 $^{1}$, 吕云波 ${ }^{1}$, 谭志卫 ${ }^{1}$, 朱 翔 $^{1}$, 赵 䂞 $^{1}$ \\ (1: 云南省环境科学研究院,昆明 650034) \\ (2: 云南省昆明市疾病预防控制中心 , 昆明 650228)
}

\begin{abstract}
摘 要: 采用 GPS 定位, 在程海设置了 3 个断面 9 个采样点, 对各种形态磷进行了为期 $1 \mathrm{a}$ 的研究, 分析了高原深水湖泊 程海磷形态分布和变化. 结果表明: 程海中总磷含量范围为 $0.008 \sim 0.155 \mathrm{mg} / \mathrm{L}$, 年平均值为 $0.046 \mathrm{mg} / \mathrm{L}$, 含量水平已经 较高. 存在形态是颗粒态总磷占 $54.35 \%$; 溶解态有机磷占 $19.56 \%$; 溶解态无机磷占 $26.09 \%$. 各形态磷时间分布和变化 与水生生物特别是浮游植物生命活动和周期变化密切相关;水平分布格局受浮游生物活动、湖流风动等综合影响; 由水 表层一亚底层垂直分布比较均匀, 湖底层含量不同程度升高.
\end{abstract}

关键词: 磷元素;赋存形态;分布;变化;程海;深水湖泊

\section{Distribution and variations of phosphorus speciation in Lake Chenghai on plateau, Yun- nan Province}

\author{
DONG Yunxian ${ }^{1}$, HONG Xuehua ${ }^{2}$, HE Bin ${ }^{1}$, LÜ Yunbo $^{1}$, TAN Zhiwei ${ }^{1}$, ZHU Xiang ${ }^{1} \&$ ZHAO Lei ${ }^{1}$ \\ (1: Yunnan Research Academy of Environmental Science, Kunming 650034, P. R. China) \\ (2: Kunming Centre for Disease Prevention and Control, Kunming 650228, P. R. China)
}

\begin{abstract}
Nine sampling sites along three sections in Lake Chenghai were established by Global Positioning System for a study on phosphorus forms in a period of a year. The characteristics of the distribution and variations of phosphorus forms in deep lake on plateau are analyzed. The results indicate that the total phosphorus content is between 0.008 and $0.155 \mathrm{mg} / \mathrm{L}$, and the annual average content is $0.046 \mathrm{mg} / \mathrm{L}$. The percent of existent state of phosphorus forms is $54.35 \%$ particulate total phosphorus, $19.56 \%$ dissolved organic phosphorus, 26.09\% dissolved inorganic phosphorus. The characteristics of the distributions and variations of phosphorus forms are closely related to vital processes and cycles of phytoplankton. The horizontal distribution pattern is easily affected by the composites effects of biological processes of plankton, and movement and feeding of lake water. The distribution of phosphorus is relatively homogenous from the surface layer to the sub-bottom layer, and increase with various degrees at the bottom layer.
\end{abstract}

Keywords: Phosphorus; combined forms; distribution; variation; Lake Chenghai; deep lake

磷是湖泊富营养化中的关键性因子, 同时也是限制性的因子, 所有有机体都需要磷来进行能量传输以 及供应生长需要 ${ }^{[1-2]}$, 水体中磷的形态和生物可利用性会影响大多数藻类的生长 ${ }^{[3]}$, 对此已有较为广泛的研 究 $^{[4-7]}$. 近年来, 国内湖泊水域磷形态转化及其潜在效应研究集中于长江中下游浅水湖泊 ${ }^{[8-13]}$ 以及云南高原 的浅水湖泊滇池 ${ }^{[14-15]}$, 对我国深水湖泊的研究相对较少, 对咸水湖和河口海岸带泻湖生态系统研究偏少 ${ }^{[16]}$. 营养盐的来源与供给是蓝藻水华暴发的一个关键因素, 至今我们对此知之甚少, 对这方面研究的深人将有 助于揭示蓝藻水华暴发机制 ${ }^{[17]}$. 本文通过对云南高原深水湖泊中不同形态磷的研究, 初步揭示程海水中磷 的分布和变化, 为认识磷在湖泊中的生物地球化学循环过程及其与蓝藻水华暴发之间的内在联系提供 参考.

* 云南省科技计划项目 (2009CA002)资助. 2011-04-19 收稿;2011-08-15 收修改稿. 董云仙,女,1964 年生,高 级工程师; E-mail:dongyunxian@ sohu. com. 


\section{1 研究区概况与研究方法}

\section{1 研究区概况}

程海 $\left(26^{\circ} 25^{\prime} \sim 26^{\circ} 40^{\prime} \mathrm{N}, 100^{\circ} 33^{\prime} \sim 100^{\circ} 45^{\prime} \mathrm{E}\right)$ 地处青藏高原与云贵高原的衔接部位, 行政区划上属于云 南省丽江市永胜县. 湖面海拔高程 $1501.0 \mathrm{~m}$, 流域面积 $318.3 \mathrm{~km}^{2}$, 湖面积 $74.6 \mathrm{~km}^{2}$, 湖体呈南北向椭圆形展 布, 南北长 $19.0 \mathrm{~km}$, 东西宽 $4.3 \mathrm{~km}$, 最大水深 $35 \mathrm{~m}$, 平均水深 $26.5 \mathrm{~m}$, 约 $87 \%$ 的水面水深达 $20 \mathrm{~m}$, 总蓄水量 $19.8 \times 10^{8} \mathrm{~m}^{3}$, 是典型的深水湖泊. 程海大约形成于新生代第三纪中期, 是喜马拉雅期造山运动形成断裂地 堑, 中陷低凹之处聚水成湖, 原来曾经是一个外流湖, 湖水通过程河向南 30 余千米流人金沙江. 据《永胜县

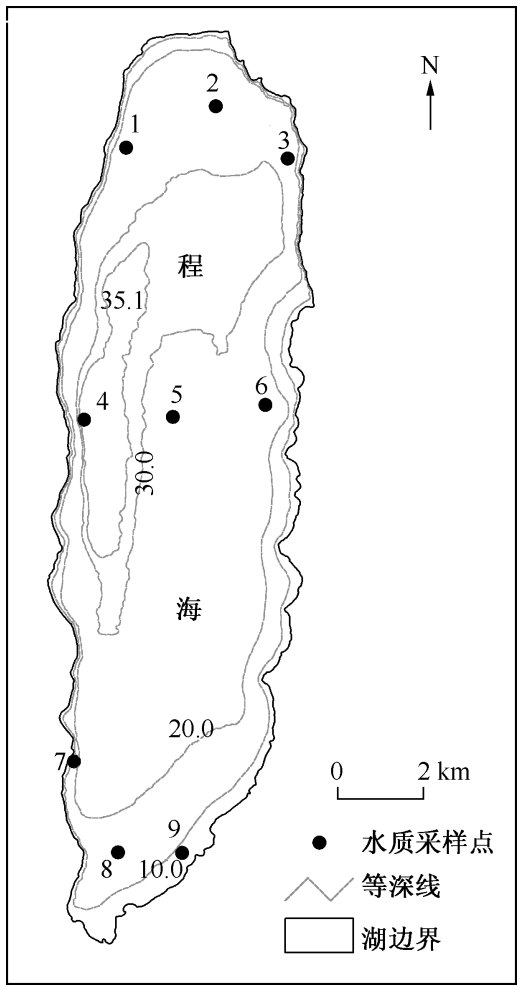

图 1 程海生态要素研究采样点分布

Fig. 1 Distribution of sampling sites about ecological elements in Lake Chenghai 志》记载, 当时平均水深 $72 \mathrm{~m}$, 在 1690 年前后, 湖水位突然下降, 成为封闭型湖泊. 湖泊封闭后, 水体交换周期无限延长, 营养物 质积累, 湖泊富营养化进程加快. 1911-1942 年, 程海初级生产 力明显变化, 生物结构明显转变 ${ }^{[18-20]}$. 改革开放以来, 在湖区 人口增加、生产生活方式转变和湖滨区螺旋藻养殖业发展的 背景下, 进入湖体的污染物质大大增加, 湖泊富营养化越加 严重.

\section{2 研究方法}

1.2.1 样点设置 在程海湖北、湖中、湖南设置三个断面, 每个 断面设左、中、右 3 个采样点,共 9 个采样点 (图 1). 其中, 中间断 面的湖中心位置 $5^{\#}$ 采样点分层采样, 分别于水表下 $0.5 、 5.0$ 、 $10.0 、 15.0 、 20.0 \mathrm{~m}$ 、离湖底 $0.5 \mathrm{~m}$ 处采集样品, 共采集 6 层样品. 每次野外采样共采集 14 个样品.

1.2 .2 采样时间 2009 年 10 月一 2010 年 9 月, 每月 15 日采样 1 次,其中,水华发生期间加密采样,合计采样 18 次.

1.2.3 水样的野外采集 到达固定采样点后, 首先对采样点进 行 GPS 定位, 测定水深、水温、透明度、pH 等物理指标, 观察水环 境状况, 并做好现场记录. 用有机玻璃采水器采集指定水层水 样, 放人事先准备好的采样桶中, 带回实验室以备分析.

1.2.4 水样的室内分析 本研究采用国家或行业标准方法, 有 关操作和质量控制按 HJ/T91-2002《地表水和污水监测技术规 范》、《水和废水监测分析方法》第四版中的 $\mathrm{A}$ 类方法进行 ${ }^{[21]}$. 水 样中 3 种存在形态磷测定流程见图 2. 其余形态磷计算方法为: 颗粒态总磷 $($ PTP $)=$ 总磷 $($ TP $)-$ 溶解态总磷 $($ DTP $)$; 溶解态有机 磷 $($ DOP $)=$ 溶解态总磷 $($ DTP $)-$ 溶解态无机磷 $($ DIP $)$

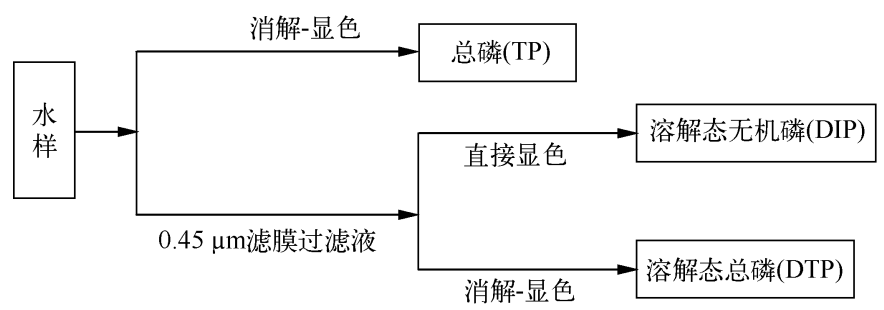

图 2 水样中 3 种形态磷测定流程图

Fig. 2 Flow chart of mesuration for three forms of phosphorus in sampling waters 


\section{2 结果}

\section{1 程海各形态磷组成与含量水平}

程海水体中的磷以各种形态存在, 它们可分为正磷酸盐、缩合磷酸盐 (焦磷酸盐、偏磷酸盐和多磷酸盐) 和有机结合磷. TP 为各种形态磷的总和, 程海中, TP 浓度变化范围为 $0.008 \sim 0.155 \mathrm{mg} / \mathrm{L}$, 年平均含量为 $0.046 \mathrm{mg} / \mathrm{L}$, 含量水平较高. 从各形态磷来看, PTP 含量为 $0.007 \sim 0.144 \mathrm{mg} / \mathrm{L}$, 年平均含量为 $0.025 \mathrm{mg} / \mathrm{L}$, 占 TP 含量的 $54.35 \%$, PTP 包括颗粒态有机磷和颗粒态无机磷酸盐两类, 前者主要是存在于生物有机体内 和有机碎屑中的各种磷化合物; 后者主要是 $\mathrm{Ca}_{3}\left(\mathrm{PO}_{4}\right)_{2} 、 \mathrm{FePO}_{4}$ 等溶解度极小的无机磷酸盐、某些悬浮的粘 土矿物和有机体表面上可能吸附的无机磷. 溶解态总磷 (DTP) 含量范围为 $0.003 \sim 0.049 \mathrm{mg} / \mathrm{L}$, 年平均含量 为 $0.021 \mathrm{mg} / \mathrm{L}$, 占 TP 含量的 $45.65 \%$, DTP 也包含 DOP 和 DIP 两类, DOP 含量范围为 $0.000 \sim 0.033 \mathrm{mg} / \mathrm{L}$, 年平均含量为 $0.009 \mathrm{mg} / \mathrm{L}$, 占 DTP 含量的 $42.86 \%$, 占 TP 含量的 $19.56 \%$, 它们主要是溶于天然水中的有机 结合态磷, 如氨基磷酸、磷核苷酸类化合物、磷蛋白、核蛋白、磷酯和糖类磷酸酯等, 目前对于 DOP 的性质还 不完全清楚. DIP 含量范围为 $0.001 \sim 0.040 \mathrm{mg} / \mathrm{L}$, 年平均值为 $0.012 \mathrm{mg} / \mathrm{L}$, 占 DTP 含量的 $57.14 \%$, 占 TP 含量的 $26.09 \%$, 它们的主要成分是 $\mathrm{PO}_{4}^{3-} 、 \mathrm{HPO}_{4}^{2-} 、 \mathrm{H}_{2} \mathrm{PO}_{4}^{-} 、 \mathrm{H}_{3} \mathrm{PO}_{4}$ 及无机缩聚磷酸盐. 在水生生态系统中, DIP 可被水生植物 (主要是浮游藻类) 直接利用 ${ }^{[22-23]}$, 它们对浮游植物生长促进作用显著 ${ }^{[24-25]}$. Mackey 等在 研究红海阿克巴湾的可利用性磷与浮游植物群体磷形态的关系时也发现, DIP 的含量水平极大影响着浮游 植物的生长状况 ${ }^{[26]}$. 因此, 水体中 DIP 的含量、分布状况和循环速率对于像程海这样富营养化深水湖泊中磷 的生物地球化学循环具有重要意义.

\section{2 程海各形态磷逐月变化特征}

2009 年 10 月一-2010 年 9 月, 程海水体中 TP 表现出 2 个高峰期和 2 个低谷期 ( 图 3 ), 第一高峰出现在冬 季 2010 年 1 月, 月平均含量高达 $0.078 \mathrm{mg} / \mathrm{L}$, 此后以铜绿微囊藻 (Microcystis aeruginosa)、水华微囊藻 (M. flos-aquae) 为主的程海冬季水华暴发 ${ }^{[27]}$; TP 年内第二高峰出现在 2010 年 5 月, 这次高峰的出现与卷曲 鱼腥藻 (Anabaena circinalis) 为主的程海春季水华暴发期相吻合. PTP 年内也呈现 2 个波峰和 2 个波谷, 出现 时段与 TP 基本一致, 多由于藻体富集和藻体死亡引起. DTP 年内变动有 1 个明显的高峰和 1 个明显的低谷 期, 秋末初冬, 水中 DTP 开始升高, 深冬时达到其年内最高峰, 为 $0.044 \mathrm{mg} / \mathrm{L}$ ( 1 月 ), 高于全湖年平均值 $109.5 \%$, 此后 DTP 呈下降趋势, 6 月降至最低值 $(0.011 \mathrm{mg} / \mathrm{L})$. 程海中 DTP 逐月变化规律基本上反映了湖 内生物生命活动规律, 水体中 DTP 积累到一 定程度时, 刺激浮游植物大量生长, 由于浮 游植物生物量急剧增加, 又导致了水体中 DTP 降低至年内最低谷. DOP 年内也有 2 个 波峰和 2 个波谷的变动, 而 DIP 仅有 1 个较 明显的高峰和 1 个较明显的低谷出现, 进人 夏末秋初后 DIP 逐渐积累, 到深冬季节达其 年内最高峰 (1月), 此后, 随着冬季铜绿微 囊藻水华和春季卷曲鱼腥藻水华暴发性生 长, DIP 逐步降低, 在春末水华后期降至其年 内最低谷 $(5-7$ 月), 因此, 如同 DTP 一样, 程海中 DIP 的时间分布节律与湖内生物生 命活动节律关系密切.

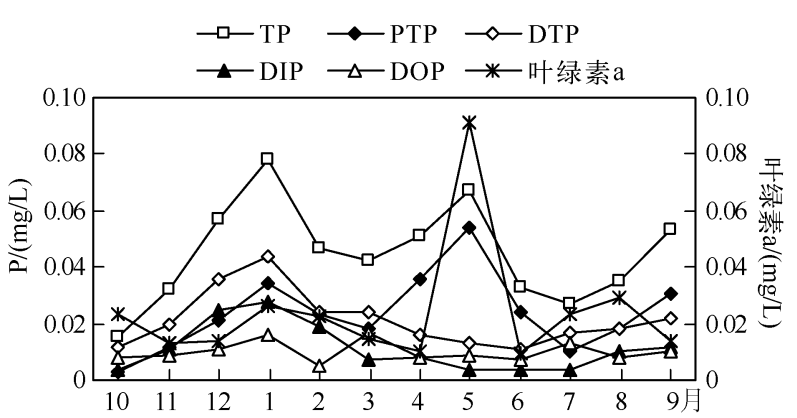

图 $32009-2010$ 年程海各形态磷和叶绿素 a 逐月变化

Fig. 3 Monthly variation of different forms of phosphorus and chlorophyll-a in Lake Chenghai during 2009-2010

\section{3 程海各形态磷水平分布特征}

程海表层水中 TP 与 PTP 水平分布特征颇为相似, $1^{\#}$ 采样点最高, 其中, TP 比全湖平均水平偏高 $13.0 \%$; PTP 比全湖平均水平偏高 $33.3 \%$, 原因是 2010 年 5 月春季水华时, 湖区盛行的南风(时有东风) 将水华吹 于 $1^{\#}$ 采样点附近堆积, 藻类腐烂分解, 释放营养物质, 造成该区域 TP 与 PTP 含量陡增, 因此 $1^{\#}$ 采样点年平 均值偏高; TP 含量最低的区域是湖中心 $5^{\#}$ 采样点, 该区域年平均含量为 $0.043 \mathrm{mg} / \mathrm{L}$, 比全湖平均值仅偏 
低 $0.003 \mathrm{mg} / \mathrm{L}$, 折成百分率偏低 $6.5 \%$; PTP 含量最低的区域是湖西南部 $7^{\#}$ 采样点, 该区域年平均含量为 $0.020 \mathrm{mg} / \mathrm{L}$, 比全湖平均值仅偏低 $0.004 \mathrm{mg} / \mathrm{L}$, 折成百分率偏低 $16.7 \%$; 实际上, TP 与 PTP 除在 $1^{\#}$ 采样点明 显偏高外,其余区域差异并不大. DTP 的分布与 PTP 相反,PTP 低的区域 DTP 高, PTP 高的区域 DTP 则相对 较低, 其规律是: 湖南部 > > 湖中部 > 湖北部, 湖东南部 > > 湖中部 > 湖西北部, 湖南部平均含量高出湖北部 $24.6 \%$, 湖东南部平均含量高出湖西北部 $23.7 \%$. DOP、DIP 的水平分布有一定差异但也不明显, 大体规律 是: 由湖南部一湖中部一湖北部递减, 由湖东部一湖中部一湖西部递减 (表 1 ). 程海表层水中磷形态水平分布 格局受浮游生物活动、湖流风动等因素综合影响.

表 1 程海表层水中各形态磷浓度 $(\mathrm{mg} / \mathrm{L})$

Tab. 1 Concentrations of different forms of phosphorus in surface water of Lake Chenghai

\begin{tabular}{|c|c|c|c|c|c|c|}
\hline 采样点 & 浓度 & $\mathrm{TP}$ & РTP & DTP & DOP & DIP \\
\hline \multirow[t]{2}{*}{ 小阳保 ( $1^{\#}$ ) } & 变化范围 & $0.024 \sim 0.155$ & $0.004 \sim 0.144$ & $0.007 \sim 0.041$ & $0.002 \sim 0.015$ & $0.002 \sim 0.032$ \\
\hline & 年平均值 & 0.052 & 0.032 & 0.019 & 0.008 & 0.011 \\
\hline \multirow[t]{2}{*}{ 北部湖心 $\left(2^{\#}\right)$} & 变化范围 & $0.019 \sim 0.097$ & $0.002 \sim 0.082$ & $0.003 \sim 0.045$ & $0.001 \sim 0.020$ & $0.002 \sim 0.030$ \\
\hline & 年平均值 & 0.045 & 0.025 & 0.019 & 0.009 & 0.011 \\
\hline \multirow[t]{2}{*}{ 青草湾( $3^{\#}$ ) } & 变化范围 & $0.021 \sim 0.081$ & $0.008 \sim 0.057$ & $0.005 \sim 0.044$ & $0.001 \sim 0.020$ & $0.001 \sim 0.026$ \\
\hline & 年平均值 & 0.044 & 0.025 & 0.019 & 0.009 & 0.010 \\
\hline \multirow[t]{2}{*}{ 托漂( $\left.4^{\#}\right)$} & 变化范围 & $0.024 \sim 0.071$ & $0.003 \sim 0.048$ & $0.006 \sim 0.041$ & $0.001 \sim 0.020$ & $0.003 \sim 0.027$ \\
\hline & 年平均值 & 0.044 & 0.025 & 0.019 & 0.009 & 0.012 \\
\hline \multirow[t]{2}{*}{ 湖中心 $\left(5^{\#}\right)$} & 变化范围 & $0.021 \sim 0.079$ & $0.004 \sim 0.035$ & $0.005 \sim 0.044$ & $0.002 \sim 0.033$ & $0.002 \sim 0.027$ \\
\hline & 年平均值 & 0.043 & 0.022 & 0.021 & 0.011 & 0.010 \\
\hline \multirow[t]{2}{*}{ 昔拉湾 (6 $6^{\#}$ ) } & 变化范围 & $0.029 \sim 0.073$ & $0.002 \sim 0.045$ & $0.012 \sim 0.045$ & $0.001 \sim 0.020$ & $0.005 \sim 0.034$ \\
\hline & 年平均值 & 0.047 & 0.023 & 0.023 & 0.008 & 0.015 \\
\hline \multirow[t]{2}{*}{ 金篮村 $\left(7^{\#}\right)$} & 变化范围 & $0.033 \sim 0.073$ & $0.003 \sim 0.032$ & $0.013 \sim 0.049$ & $0.001 \sim 0.023$ & $0.002 \sim 0.040$ \\
\hline & 年平均值 & 0.045 & 0.020 & 0.024 & 0.010 & 0.014 \\
\hline \multirow[t]{2}{*}{ 南部湖心 $\left(8^{\#}\right)$} & 变化范围 & $0.032 \sim 0.075$ & $0.002 \sim 0.036$ & $0.008 \sim 0.044$ & $0.003 \sim 0.027$ & $0.002 \sim 0.033$ \\
\hline & 年平均值 & 0.046 & 0.022 & 0.023 & 0.010 & 0.012 \\
\hline \multirow[t]{2}{*}{ 欧阳村( $\left.9^{\#}\right)$} & 变化范围 & $0.034 \sim 0.086$ & $0.002 \sim 0.045$ & $0.011 \sim 0.041$ & $0.002 \sim 0.020$ & $0.002 \sim 0.031$ \\
\hline & 年平均值 & 0.047 & 0.022 & 0.024 & 0.011 & 0.012 \\
\hline
\end{tabular}

\section{4 程海湖心各形态磷时空变化特征}

程海湖心各形态磷时空分布有一定的差异 (图 4),其中,TP、PTP 在 2010 年 1 月前后含量高而且变化较 为剧烈, DOP、DIP 在 2009 年 11 月一 2010 年 4 月变化剧烈,这是程海冬季水华 ${ }^{[28]}$ 和春季水华暴发的环境效 应. 各形态磷由水表层至 $20.0 \mathrm{~m}$ 水层分布相对均匀, 而湖底层含量不同程度地高于其上水层, 可能的原因 有: (1) 采样时操作存在问题, 搅动沉积物, 悬浮于水中的沉积物造成各形态磷测定结果偏高; (2) 剧烈的湖水 运动扰动湖底沉积物再悬浮; (3) 大量补给的地下水已经受到污染; (4) 底泥释放, 具体是何种原因, 有待进一 步研究甄别.

\section{3 结论}

1) 程海水体中 TP 浓度变动范围为 $0.008 \sim 0.155 \mathrm{mg} / \mathrm{L}$, 年平均值为 $0.046 \mathrm{mg} / \mathrm{L}$, 含量水平已经较高.

2) 从各形态磷来看, PTP 含量为 $0.025 \mathrm{mg} / \mathrm{L}$, 占 TP 含量的 $54.35 \%$; DTP 含量为 $0.021 \mathrm{mg} / \mathrm{L}$, 占 TP 的 $45.65 \%$; DOP 含量为 $0.009 \mathrm{mg} / \mathrm{L}$, 占 TP 含量的 $19.56 \%$; DIP 含量为 $0.012 \mathrm{mg} / \mathrm{L}$, 占 TP 的 $26.09 \%$, 磷的存 在特点是 DIP 含量比重较大, 说明在程海这样的富营养化深水湖泊中, DIP 的含量、分布状况和循环速率对 整个湖泊磷生物地球化学循环具有重要意义.

3 ) 年周期逐月变化中,TP、PTP 和 DOP 表现出 2 个高峰期和 2 个低谷期; DTP 和 DIP 仅有 1 个较明显 的高峰期和 1 个较明显的低谷期,研究表明程海水中各个形态磷的时间变化特征与水生生物特别是浮游植 物生长、衰老、死亡、分解等生命活动和周期变化密切相关.

4 ) 表层水中,TP 和 PTP 除在 $1^{\#}$ 采样点明显偏高外,其余区域差异不大;DTP 的分布与 PTP 相反;DOP、 

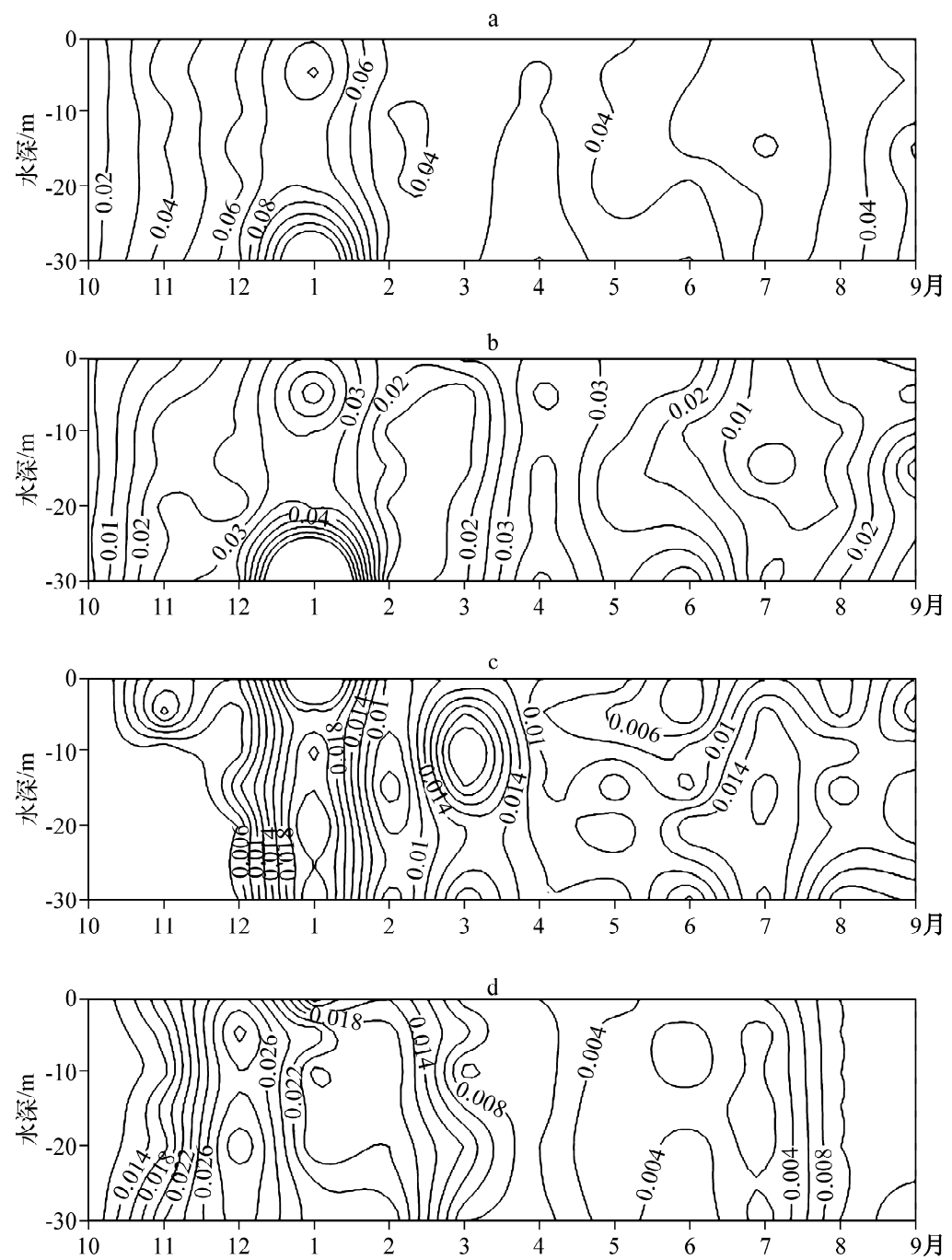

图 $42009-2010$ 年程海湖心 $\mathrm{TP}(\mathrm{a}) 、 \mathrm{PTP}(\mathrm{b}) 、 \mathrm{DOP}(\mathrm{c})$ 和 $\operatorname{DIP}(d)$ 浓度时空变化等值线图

Fig. 4 Isoline map of temporal and spatial variation of $\operatorname{TP}(a), \operatorname{PTP}(b), \operatorname{DOP}(c)$ and $\operatorname{DIP}(d)$ concentrations in the middle of Lake Chenghai during 2009-2010

DIP 的水平分布有一定差异但也不明显. 磷形态分布格局受浮游生物活动、湖流风动等因素综合影响.

5 ) 程海湖心磷形态时空分布有一定的差异, 这是程海冬季水华和春季水华暴发的环境效应, 各形态磷由 表层至 $20.0 \mathrm{~m}$ 水层相对均匀, 而湖底层含量不同程度地高于其上水层,具体原因有待更深人细致的研究.

致谢: 永胜县程海管理局罗杰、贺占生、皮之强、胡锦乾等同志帮助野外采样; 云南施普瑞生物工程有限公司 程海螺旋藻养殖厂中心实验室左仕陆、武金昆、朱春锡、李志能、唐美凤、陈云梅等同志协助水化学分析工 作,在此表示哀心感谢!

\section{4 参考文献}

[ 1 ] Smith VH, Joye SB, Howarth RW. Eutrophication of freshwater and marine ecosystems. Limnol Oceanogr, 2006, 51(1, part2) : 351-355.

[ 2 ] Schindler DW. Recent advances in the understanding and management of eutrophication. Limnol Oceanogr, 2006, 51(1, 
part2) : 356-363.

[ 3 ] Peterson BJ, Barlow JP, Savage AE. The physiological state with respect to phosphorus of Cayuga Lake phytoplankton. Limnol Oceanogr, 1974, 19: 396-404.

[ 4 ] Benitez-Nelson C. The biogeochemical cycling of phosphorus in marine systems. Earth Sci Rev, 2000, 51: 109-135.

[ 5 ] Taft JL, Loftus ME, Taylor WR. Phosphate uptake from phosphomonoesters by phytoplankton in the Chesapeake Bay. Limnol Oceanogr, 1977, $22(6)$ : 1012-1021.

[ 6 ] Deborde J, Anschutz P, Chaillou G et al. The dynamics of phosphorus in turbid estuarine systems: Example of the Gironde estuary(France). Limnol Oceanogr, 2007, 52(2) : 862-872.

[ 7 ] Smith VH. Responses of estuarine and coastal marine phytoplankton to nitrogen and phosphorus enrichment. Limnol Oceanogr, 2006, 51(1, part 2) : 377-384.

[8] 袁和忠, 沈 吉, 刘恩峰等. 太湖水体及表层沉积物磷空间分布特征及差异性分析. 环境科学, 2010, 31 (4): 954-960.

[9] 邓建才, 陈 桥, 崔水晶等. 太湖水体中氮、磷空间分布特征及环境效应. 环境科学, 2008, 29(2): 3382-3386.

[10] 秦伯强, 朱广伟. 长江中下游地区湖泊水和沉积物中营养盐的赋存、循环及其交换特点. 中国科学: D 辑, 2005, 35 (增刊) : 1-10.

[11] 孙晓杭, 张 昱, 杨 敏等. 太湖悬浮物磷的形态分布特征. 安全与环境学报, 2005, 5(4): 19-22.

[12] 朱广伟, 秦伯强, 高 光等. 长江中下游浅水湖泊沉积物中磷的形态及其水相磷的关系. 湖泊科学, 2004,24 (3) : 381-388.

[13] 范成新, 张 路, 秦伯强等. 风浪作用下太湖悬浮态颗粒物中磷的动态释放估算. 中国科学: D 辑, 2003,33 (8) : 760-768.

[14] 陈永川, 张德刚, 汤 利. 滇池水体磷的时空变化与藻类生长的关系. 生态环境学报, 2010, 19(6): 1363-1368.

[15] 陈永川, 汤 利, 湛 丽等. 滇池水体中磷的时空变化特征研究. 农业环境科学学报, 2005, 24(6): 1145-1151.

[16] 黄清辉, 王 否, 王子健. 中国湖泊水域中磷形态转化及其潜在生态效应研究动态. 湖泊科学, 2006, 18(3): 199-206.

[17] 秦伯强. 太湖生态和环境若干问题的研究进展及其展望. 湖泊科学, 2009, 21(4) : 445-455.

[18] 吴敬禄, 蒋雪中, 夏威岗等. 云南程海近 500 年来湖泊初始生产力的演化. 海洋地质与第四纪地质, 2002,22 (2) : 95-98.

［19］吴敬禄, 王苏民. 云南程海富营养化过程的碳氮稳定同位素示踪. 第四纪研究, 2003, 23(5): 557-564.

[20] 万国江, 陈敬安, 胥思勤等. ${ }^{210} \mathrm{~Pb}_{\mathrm{ex}}$ 沉积通量突然增大对湖泊生产力的指示一一以程海为例. 中国科学: $\mathrm{D}$ 辑, 2004, 34(2) : 154-162.

[21] 魏复盛, 徐晓白, 阎吉昌. 水和废水监测分析方法: 第 4 版. 北京: 中国环境科学出版社, 2006.

[22] Cembella AD, Antia NJ, Harrison PJ. The utilization of inorganic and organic phosphorus compounds as nutrients by eukaryotic microalgae: A multidisciplinary perspective. Part 2. Crit Rev Microbiol, 1984, 65 : 3205-3212.

[23] Hudson JJ, Taylor WD. Measuring regeneration of dissolved phosphorus in planktonic communities. Limnol Oceanogr, 1996, 41 : 1560-1565.

[24] 李 英, 吕颂辉, 徐 宁等. 东海原甲藻对不同磷源的利用特征. 生态科学, 2005, 24(4): 314-317.

[25] 许 海, 杨林章, 茅 华等. 铜绿微囊藻、斜生栅藻生长的磷营养动力学特征. 生态环境, 2006, 15(5): 921-924.

[26] Mackey KRM, Labiosa RG, Calhoun M et al. Phosphorus availability, phytoplankton community dynamics, and taxonspecific phosphorus status in the Gulf of Aqaba, Red Sea. Limnol Oceanogr, 2007, 52(2) : 873-885.

[27] 董云仙, 金 玉, 胡锦乾等. 程海冬季水华特征、成因与控制对策. 环境科学导刊, 2010, 29(3):28-31.

[28] 董云仙, 洪雪花, 胡锦乾等. 程海冬季水华暴发期间氮、磷营养元素的形态与分布. 生态环境学报, 2010,19 (11) : 2675-2679. 